\title{
Anemia and acute coronary syndrome: current perspectives
}

This article was published in the following Dove Press journal: Vascular Health and Risk Management

\author{
Miriam Stucchi ${ }^{1}$ \\ Silvia Cantoni ${ }^{2}$ \\ Enrico Piccinelli ${ }^{3}$ \\ Stefano Savonitto ${ }^{4}$ \\ Nuccia Morici ${ }^{5,6}$ \\ 'Division of Cardiology, ASST \\ Vimercate, Italy; ${ }^{2}$ Division of \\ Hematology, ASST Grande \\ Ospedale Metropolitano Niguarda \\ Ca' Granda, Milano, Italy; ${ }^{3}$ Health \\ Science Department, Milano-Bicocca \\ University, Milano, Italy; ${ }^{4}$ Division \\ of Cardiology, A. Manzoni Hospital, \\ Lecco, Italy; ${ }^{5} \mathrm{De}$ Gasperis Cardio \\ Center, ASST Grande Ospedale \\ Metropolitano Niguarda Ca' Granda, \\ Milano, Italy; ${ }^{6}$ Department of Clinical \\ Sciences and Community Health, \\ Università degli Studi di Milano, \\ Milano, Italy
}

Correspondence: Nuccia Morici De Gasperis Cardio Center, ASST

Grande Ospedale Metropolitano

Niguarda Ca' Granda, Piazza

dell'Ospedale Maggiore, 3, Milano 20162, Italy

Tel +390264442576

Email nuccia.morici@ospedaleniguarda.it

\begin{abstract}
Reference hemoglobin $(\mathrm{Hb})$ values for the definition of anemia are still largely based on the 1968 WHO Scientific Group report, which established a cutoff value of $<13 \mathrm{~g} / \mathrm{dL}$ for adult men and $<12 \mathrm{~g} / \mathrm{dL}$ for adult nonpregnant women. Subsequent studies identified different normal values according to race and age. Estimated prevalence of anemia on admission in the setting of an acute coronary syndrome (ACS) is between $10 \%$ and $43 \%$ of the patients depending upon the specific population under investigation. Furthermore, up to $57 \%$ of ACS patients may develop hospital-acquired anemia (HAA). Both anemia on admission and HAA are associated with worse short- and long-term mortality, even if different mechanisms contribute to their prognostic impact. Baseline anemia can usually be traced back to preexisting disease that should be specifically investigated and corrected whenever possible. HAA is associated with clinical characteristics, medical therapy and interventional procedures, all eliciting cardiovascular adaptive response that can potentially worsen myocardial ischemia. The intrinsic fragility of anemic patients may limit aggressive medical and interventional therapy due to an increased risk of bleeding, and could independently contribute to worse outcome. However, primary angioplasty for ST elevation ACS should not be delayed because of preexisting (and often not diagnosed) anemia; delaying revascularization to allow fast-track anemia diagnosis is usually feasible and justified in non-ST-elevation ACS. Besides identification and treatment of the underlying causes of anemia, the only readily available means to reverse anemia is red blood cell transfusion. The adequate transfusion threshold is still being debated, although solid evidence suggests reserving red blood cell transfusions for patients with $\mathrm{Hb}$ level $<8 \mathrm{~g} / \mathrm{dL}$ and considering it in selected cases with $\mathrm{Hb}$ levels of between 8 and $10 \mathrm{~g} / \mathrm{dL}$. No evidence supports the use of iron supplements and erythropoiesis-stimulating agents in the setting of ACS.
\end{abstract}

Keywords: anemia, acute coronary syndrome, hemoglobin, red blood cell transfusion

\section{Introduction}

Anemia in the setting of acute coronary syndrome (ACS) has an established adverse prognostic value. Its impact on outcome appears to be independent of underlying causative factors - most often multiple - and time of onset, either it being preexisting the ACS or developing during hospitalization or at follow-up. In both settings, anemia has been shown to be an independent predictor of short- and long-term mortality. ${ }^{1-13}$

However, anemia must be put in perspective, keeping in mind that the main role of hemoglobin $(\mathrm{Hb})$ is to provide adequate oxygen supply to body tissues. Therefore, its concentration in blood will vary according to body mass, with resultant physiological lower levels in most women. ${ }^{1,2}$ As shown in Figure 1, when considering overt anemia, 


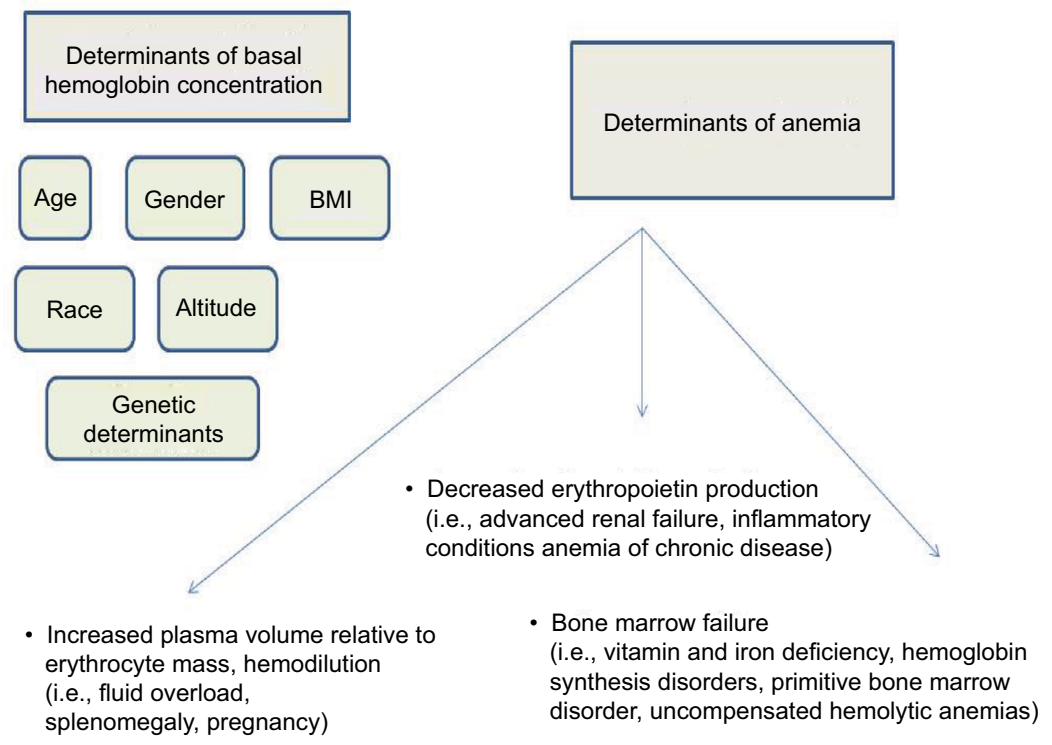

Figure I Determinants of anemia.

Abbreviation: BMI, body mass index.

3 main determinants need to be considered: adequate erythropoiesis - that is, bone marrow function and adequate production of the specific growth factor; erythropoietin - that is, renal function - and preserved red blood cell (RBC) massto-plasma volume ratio - that is, hemodilution. ${ }^{3-8}$

All these pathogenetic determinants may be deranged in patients with ischemic heart disease, leading to abnormalities in $\mathrm{Hb}$ levels. Addressing the mechanism(s) underlying the development of anemia in a specific patient may help to correct anemia, and possibly overcome or lessen its negative prognostic impact in the setting of ACS (Figure 2).

The aim of this article is to present an overview of current evidence regarding epidemiology, pathophysiology, prognostic role and therapeutic management of anemia in patients with ACS.

\section{Definition of anemia and clinical determinants of $\mathrm{Hb}$ levels}

Anemia is accurately defined as an absolute decrease in RBC mass as determined by radiolabeled blood volume analysis. ${ }^{14}$ However, the definition adopted in clinical practice commonly refers to the derived parameters, $\mathrm{Hb}$ and hematocrit (Hct).

Reference $\mathrm{Hb}$ values for the definition of anemia are still largely based on the 1968 WHO Scientific Group report, which established an $\mathrm{Hb}$ cutoff value of $<13 \mathrm{~g} / \mathrm{dL}$ for adult men and $<12 \mathrm{~g} / \mathrm{dL}$ for adult nonpregnant women. ${ }^{15}$ This definition is more a derivative of normal distribution of $\mathrm{Hb}$ concentrations and observed SDs from "average", which is assumed to be the same as "normal". More recently, several research groups tried to redefine anemia taking into account clinical variables in order to give more accurate estimates of normal values.

In 2006, a new cutoff for anemia was suggested by Beutler and Waalen ${ }^{16}$ based on 2 large databases: the NHANES-III, the third US National Health and Nutrition Examination Survey, and the Scripps-Kaiser survey conducted in the San Diego area between 1998 and 2002. In these analyses, normal $\mathrm{Hb}$ levels were set taking into account not only sex but also race and age. Results showed that people of African ancestry have at least $0.5 \mathrm{~g} / \mathrm{dL}$ lower Hb levels compared to Caucasians, and people $>60$ years of age have lower $\mathrm{Hb}$ levels compared with younger adults. ${ }^{16}$

The role of age in determining $\mathrm{Hb}$ levels was confirmed in 2008 by Patel et al who demonstrated that the mean $\mathrm{Hb}$ concentration in men was lower and variance was greater with each ascending age group from 50 to $>80$ years. ${ }^{17}$ The reasons of this variability reside in some specific characteristics of older adults, summarized in Table 1.

Our group specifically addressed the issue of anemia in elderly patients hospitalized for ACS. ${ }^{18}$ Anemia is especially frequent in this specific patient population, being detected in up to $43 \%$ of elderly patients admitted for acute heart disease, ${ }^{19}$ and its independent adverse prognostic impact is well recognized. ${ }^{20}$ Our analysis was specifically aimed at assessing the role of 2 common conditions known to be 
Anemia-induced compensatory mechanisms

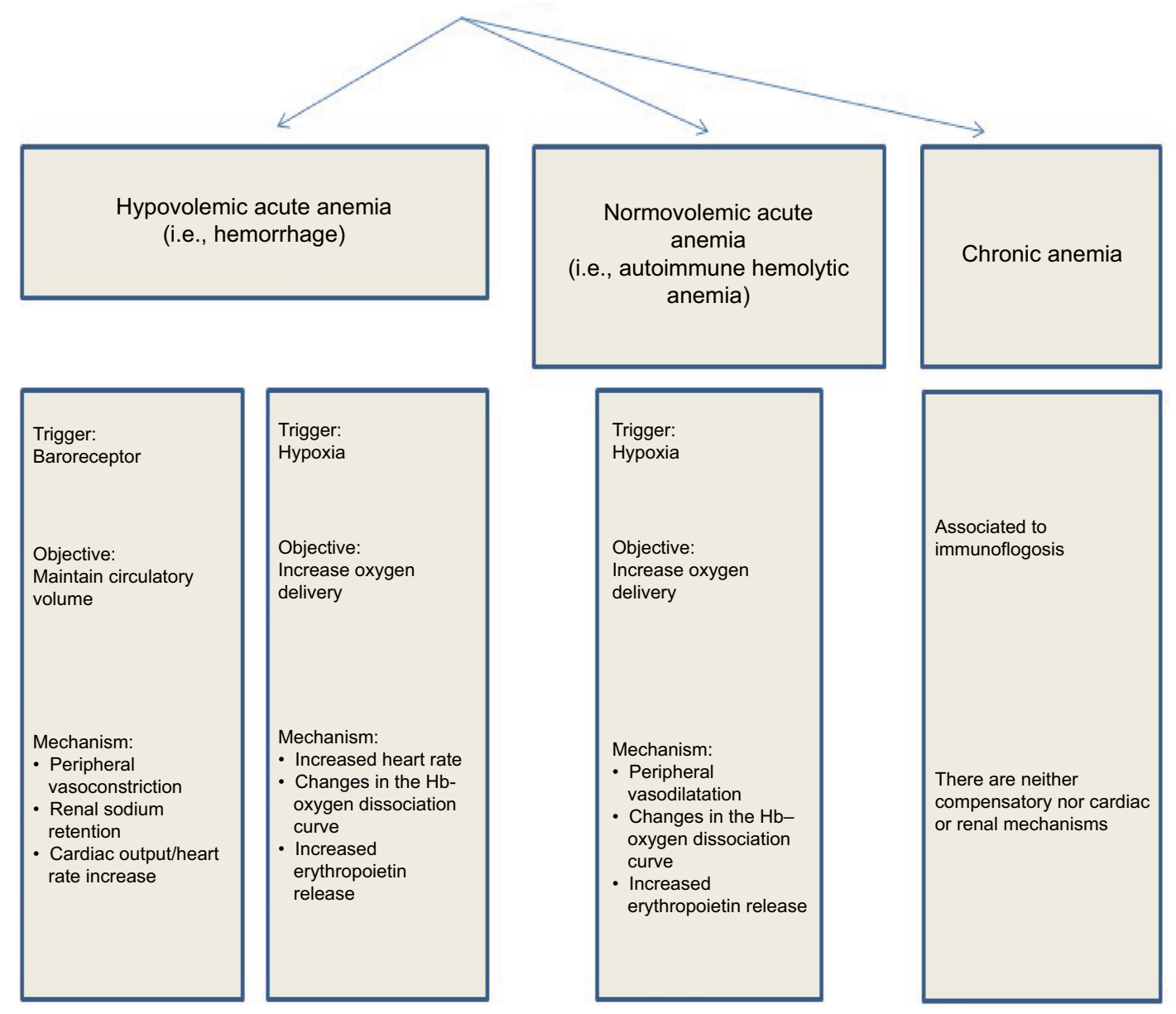

Figure 2 Anemia-induced compensatory mechanisms.

Table I Characteristics related to anemia in the elderly

- Sarcopenia: the reduced muscle mass lowers the peripheral oxygen demand and, therefore, causes a physiologic reduction in circulating blood mass

- Stem cell alteration: older patients normally have lower cellular bone marrow and hematopoietic colony-forming unit

- Different hormone levels (mainly sex hormone)

- Reduced erythropoietin induction secondary to hypoxia related to renal disfunction

- Impaired inflammatory answer: the slowdown catabolism of cytokine and minor anti-inflammatory action of sex hormone induce an extension of inflammatory answer also after the stimulus removal

associated with lower $\mathrm{Hb}$ levels: impaired renal function and body mass index (BMI) as surrogate markers for sarcopenia. An elderly population (aged $\geq 75$ years) admitted for non-ST elevation ACS (NSTEACS) and enrolled in the prospective Italian Elderly ACS study was analyzed. Although anemia was confirmed to be an independent predictor of mortality, even after adjustment for the most relevant covariates, our results demonstrated that the relationship between anemia and age per se or estimated glomerular filtration rate or BMI was weak. These results stress the concept that physiological lowering of $\mathrm{Hb}$ levels does not necessarily translate into overt anemia. When present, even in elderly subjects with multiple comorbidities, anemia should be viewed as a marker of an underlying disease state and should be specifically investigated as such and corrected whenever possible. ${ }^{18}$

Hemodilution is an additional, and often overlooked, confounding determinant of decreased $\mathrm{Hb}$ levels in patients affected by ACS and concomitant heart failure. Heart failure leads to chronic fluid overload and may be associated with splenomegaly of varying degrees. Extent of fluid overload is difficult to be precisely estimated based solely on clinical evaluation. Very few studies addressed the issue of fluid overload in patients with advanced heart failure. However, when more accurate measurement of RBC mass relative to plasma volume using $\mathrm{I}^{131}$-tagged albumin was performed, 
the low $\mathrm{Hb}$ levels turned out to be linked to fluid overload in $40 \%-46 \%$ of patients. ${ }^{14,21}$

\section{Anemia and ACS: epidemiology and prognostic impact \\ Anemia on admission}

Several studies addressed the prevalence of anemia on admission in the setting of ACS, ${ }^{1-8,18}$ with estimates varying between $10 \%$ and $43 \%$ as summarized in Table 2 .

Differences in prevalence can be traced back to multiple factors related to the specific population analyzed. For example, the prevalence of anemia is higher in patients from the Middle East where disorders of $\mathrm{Hb}$ synthesis are more frequently found. ${ }^{6}$ Nutritional deficits may also account for higher prevalence rates. ${ }^{6}$ As already mentioned, studies focusing on elderly patients usually report the highest figures.

In both randomized trials and meta-analyses, anemia on admission is always related to worse outcome, being associated with increased mortality at different observation time points, as summarized in Table $3 .^{3-6,8,9,18}$

\section{Hospital-acquired anemia (HAA)}

HAA, defined as development of new anemia developing during hospitalization, is often observed in patients admitted for an ACS.

In the study by Salisbury et al, ${ }^{10}$ the prevalence of HAA was investigated in a cohort of 17,676 patients with acute myocardial infarction and normal admission $\mathrm{Hb}$. Applying the age-, sex- and race-specific criteria described by Beutler and Waalen, ${ }^{16}$ HAA was diagnosed in those patients whose nadir $\mathrm{Hb}$ level fell during hospitalization below the set diagnostic threshold for anemia. Overall prevalence of HAA was $57 \%$, with mild $(\mathrm{Hb}>11 \mathrm{~g} / \mathrm{dL})$, moderate $(\mathrm{Hb} 9-11 \mathrm{~g} / \mathrm{dL})$ and severe HAA $(\mathrm{Hb}<9 \mathrm{~g} / \mathrm{dL})$ accounting for $37 \%, 15 \%$ and $5 \%$ of patients, respectively. The presence and severity of HAA were associated with most of the clinical characteristics also associated with anemia on admission, namely, age, female sex, history of cardiovascular risk factors and chronic kidney disease. Cardiogenic shock, acute renal failure and extensive use of antiplatelet and anticoagulation therapies were identified as additional, in-hospital determinants of HAA. In-hospital mortality rates differed according to the severity of HAA, with higher rates being observed in patients with either mild moderate (adjusted odds ratio [OR] 1.38, 95\% CI: 1.10-1.73) or severe HAA (adjusted OR 3.39, 95\% CI: 2.59-4.44) compared with not anemic patients. ${ }^{10}$

HAA has also been associated with long-term outcome. Results in smaller cohorts of patients linked the highest in-hospital $\mathrm{Hb}$ drop to worse 6-month outcome in terms of mortality (adjusted HR of 1.83\%, 95\% CI: 1.08-3.11, $p=0.026$ ) and death/myocardial infarction (adjusted HR $1.6 \%, 95 \%$ CI: $1.04-2.44, p=0.031) .{ }^{11}$ One-year mortality and cardiovascular morbidity were also higher (HR 2.47, 95\% CI: $1.23-4.96, p=0.01){ }^{12}$

HAA that does not resolve after discharge may have adverse long-term prognostic implications. In a group of 1065 patients studied by Hasin et al, ${ }^{13}$ anemia of any severity was present at discharge in $35 \%$ of cases. At a median follow-up of 27 months (range 12-44 months), the authors found that anemia had resolved in $15 \%$ of the patients and persisted in $19 \%$. In $5 \%$ of the patients, new-onset anemia (defined as an $\mathrm{Hb}$ decrease of at least $0.5 \mathrm{~g} / \mathrm{dL}$ compared to hospital discharge values) developed. Long-term outcome, defined as all-cause mortality and rehospitalization for acute heart failure, of those patients whose HAA resolved over time was similar to that of patients who were not anemic (HR 0.8, 95\% CI: 0.5-1.3). Conversely, the event rates were markedly increased in those patients with either persistent (HR 1.8, 95\% CI: 1.2-2.5) or new-onset (HR 1.9, 95\% CI: $1.1-3.3)$ anemia. ${ }^{13}$

Table 2 Prevalence of baseline anemia in ACS studies

\begin{tabular}{lllll}
\hline Authors, year & $\mathbf{N}$ & Population & Nation, special note & Prevalence \\
\hline Wu et al, ${ }^{\prime} 200 \mathrm{I}$ & 78,974 & AMl, $\geq 65$ years old & USA & $43.4 \%$ \\
Archbold et al, ${ }^{2} 2006$ & 2310 & ACS & UK & $29.7 \%$ women \\
& & & & $23.2 \%$ men \\
Meneveau et al, ${ }^{3} 2009$ & 1410 & ACS & France & $27 \%$ \\
Tsujita et al, ${ }^{4} 2010$ & 3153 & STEACS & Multinational & $10.5 \%$ \\
Sulaiman et al, ${ }^{5} 2011$ & 7922 & ACS & Middle East countries & $28 \%$ \\
Kunadian et al, ${ }^{6} 2014$ & 13,032 & NSTEACS & Multinational & $16.9 \%$ \\
Shiraishi et al, ${ }^{7} 2014$ & 1447 & Primary PCl in AMI & Japan & $25.8 \%$ \\
Morici et al, ${ }^{8} 2014$ & 637 & NSTEACS, $\geq 75$ years old & Italy & $37.7 \%$ \\
Yazji et al, ${ }^{8} 2017$ & 1731 & ACS & UK & $26.9 \%$ \\
\hline
\end{tabular}

Abbreviations: ACS, acute coronary syndrome; AMI, acute myocardial infarction; N, number of in-study patients; NSTEACS, non-ST-elevation acute coronary syndrome; $\mathrm{PCl}$, percutaneous coronary intervention; STEACS, ST-elevation acute coronary syndrome. 
Table 3 Outcome related to baseline anemia in ACS studies

\begin{tabular}{|c|c|c|c|c|c|}
\hline Authors, year & $\mathbf{N}$ & Population & Outcome & Investigation time & Risk (95\% Cl) \\
\hline Meneveau et al, ${ }^{3}$ & 1410 & ACS & Mortality & In-hospital & HR 2.1 \\
\hline 2009 & & & & 30 days & HR 2.3 \\
\hline \multirow[t]{2}{*}{ Tsujita et al, ${ }^{4} 2010$} & 3153 & STEACS & All-cause mortality & I year & HR I.98 (1.05-3.73) \\
\hline & & & Major bleeding & I year & HR 2.15 (1.43-3.24) \\
\hline \multirow[t]{3}{*}{ Sulaiman et al, ${ }^{5} 201 \mathrm{I}$} & 7922 & ACS & Mortality & In-hospital & OR I.7I (I.34-2.I7) \\
\hline & & & & 30 days & OR $1.34(1.06-1.71)$ \\
\hline & & & & I-year & OR I.22 (1.01-1.49) \\
\hline \multirow[t]{10}{*}{ Kunadian et al, ${ }^{6} 2014$} & 13,032 & NSTEACS & Composite & In-hospital & RR I.39 (1.17-1.67) \\
\hline & & & ischemic event & 30 days & RR I.40 (I.20-I.62) \\
\hline & & & & I year & RR I.48 (I.33-I.64) \\
\hline & & & & & HR I.23 (1.05-1.44) \\
\hline & & & Mortality & In-hospital & RR $2.07(1.3 \mathrm{I}-3.26)$ \\
\hline & & & & 30 days & RR 2.23 (1.64-3.02) \\
\hline & & & & I year & RR 2.35 (1.94-2.84) \\
\hline & & & & & HR I.77 (I.29-2.44) \\
\hline & & & Major bleeding & In-hospital & RR $2.20(1.84-2.64)$ \\
\hline & & & & 30 days & RR 2.30 (1.94-2.73) \\
\hline \multirow[t]{2}{*}{ Morici et al, ${ }^{18} 2014$} & 637 & NSTEACS, & Mortality & I year & HR $1.72(1.14-2.60)$ for $\mathrm{Hb} 10-13 \mathrm{~g} / \mathrm{dL}$ \\
\hline & & $\geq 75$ years old & & & HR $2.50(1.35-4.57)$ for $\mathrm{Hb}<10 \mathrm{~g} / \mathrm{dL}$ \\
\hline Yazji et al, ${ }^{8} 2017$ & $|73|$ & ACS & Mortality & I year & OR $2.42(1.40-4.16)$ \\
\hline \multirow[t]{6}{*}{ Lawler et al, ${ }^{9} 2013$} & 233,144 & ACS & Mortality & In-hospital & RR $2.76(1.94-3.92)$ \\
\hline & & & & 30 days & RR 2.81 (I.9I-4.14) HR I.75 (I.02-3.0I) \\
\hline & & & & I year & RR I.69 (I.17-2.43) \\
\hline & & & & Maximum (mean 18 months) & HR I.63 (I.I0-2.40) \\
\hline & & & & & RR 2.08 (I.70-2.55) HR I.49 (I.23-I.8I) \\
\hline & & & Re-infarction & Maximum (mean 18 months) & RR I.25 (0.78-2.02) \\
\hline
\end{tabular}

Abbreviations: ACS, acute coronary syndrome; HR, hazard ratio; N, number of in-study patients; NSTEACS, non-ST-elevation acute coronary syndrome; OR, odds ratio; $\mathrm{RR}$, relative risk; STEACS, ST-elevation acute coronary syndrome.

\section{Prognostic impact of anemia in ACS: a pathophysiologic prospective}

In the majority of patients with heart disease, anemia of chronic disease (ACD) is diagnosed. ACD is associated with a number of conditions characterized by acute or chronic immune activation, ${ }^{22}$ including heart disease, and it has also been referred to as "anemia of inflammation". ${ }^{23}$ This specific entity should be viewed as part of the systemic inflammatory response syndrome, a first-line defensive strategy phylogenetically developed to fight microbial infections. Iron increases the virulence of most pathogens, ${ }^{24,25}$ and the release of acute-phase cytokines (tumor necrosis factor $\alpha$, interleukin (IL)-1, IL-6) is associated with reduced iron availability and iron-restricted hemopoiesis, ${ }^{23}$ as shown in Table 4. In a way, anemia associated with the systemic inflammatory response syndrome can be envisioned as the price the organism has to pay to better face infection. However, if not associated with other aggravating cofactors and being part of a protective defense strategy, ACD is seldom severe and detrimental to the organism. In this perspective, the mild anemia so often found in ischemic heart disease patients may not represent
Table 4 Effects of inflammatory response mediated by cytokines (IL-I, IL-6, TNF $\alpha$, IFN $\gamma$, TGF $\beta$ )

- Shorter half-life of red blood cells

- Antiproliferative action against endothelial progenitor cells

- Low iron availability for emopoiesis

- Reducted erithropoietin productiosn

- Minor response of hematopoietic progenitors to stem cell factor and EPO for receptor downregulation

a negative prognostic marker per se. Conversely, it might be viewed as a marker of a preexisting, systemic underlying disease state defining a "more fragile" patient.

In a recent survey, Mamas et al examined the correlates and associations between anemia and subsequent cardiovascular risk in a large retrospective cohort of patients presenting with ACS and found that patients with anemia had more comorbidities compared with their counterparts with normal $\mathrm{Hb}$ levels. Moreover, several preexisting factors were independently associated with anemia: smoking, hyperlipidemia, angina, previous myocardial infarction, previous heart failure, previous stroke, peripheral vascular disease, 
diabetes mellitus, chronic obstructive pulmonary disease, renal disease and previous coronary intervention. ${ }^{26}$

A role for the systemic inflammatory response syndrome has been suggested also in reducing the capacity for vascular healing. Solomon et al found decreased levels of peripheral circulating endothelial progenitor cells in ACS patients affected by anemia on admission compared to non-anemic subjects. They hypothesize that, in addition to a preexisting inflammatory condition, the systemic effects of the inflammatory response induced by myocardial necrosis are not just limited to blunted erythroid function but also involve the ability to produce or mobilize endothelial progenitor cells by the bone marrow. This, in turn, may compromise the vascular healing capacity and contribute to poor prognosis of patients with ACS and anemia. ${ }^{27}$

Anemia has been linked to worse prognosis in a number of different clinical settings. While it is still unclear whether mild anemia directly leads to poor outcomes, it is reasonable to hypothesize that it may reflect a more severe underlying systemic illness. ${ }^{28}$

\section{Prognostic impact of anemia in ACS: the role of suboptimal treatment}

Aside from pathophysiological considerations, anemia may impact on the outcome because anemic patients may not receive guideline-recommended treatment for ACS.

This data has emerged from the Biennial Israeli ACS registry (ACSIS) which prospectively enrolled 5600 patients with ACS. Because of a perceived increased hemorrhagic risk, coronary angiography was performed less frequently in patients with anemia compared with patients without anemia (77\% vs. 91\%, $p<0.001)$. Among patients with anemia who underwent coronary angiography, the majority (95\%) had obstructive coronary disease, and $78 \%$ of them were triaged to revascularization. Among anemic patients, an invasive approach was associated with lower mortality at 30 days and at 1 year, with no significant excess in major bleeding. ${ }^{29}$ Indeed, in-hospital bleeding complications have been reduced by the almost universal use of the radial percutaneous approach to coronary intervention, as well as more selective use of GPIIb/IIIa receptor blockers and heparins. ${ }^{30}$

The lack of clarity in contemporary guideline recommendations as to how patients with anemia should be treated has also affected post-discharge treatment.

In a retrospective cohort of 422,855 patients with ACS enrolled between January 2006 and December 2010 in the UK, similar rates of angiography were observed in the anemic vs. non-anemic patients. However, anemic patients were significantly less likely to be prescribed secondary prevention medications. In this large cohort study, the impact of anemia on mortality was independent and almost comparable across the ACS spectrum. ${ }^{26}$

\section{Anemia and ACS: to treat or not to treat?}

In the complex scenario of ACS, the balance between risks and benefits of RBC transfusion is likely to be influenced by multiple factors. From a theoretical point of view, transfusing $\mathrm{RBC}$ increases oxygen delivery to the vulnerable myocardium, reducing ischemic symptoms, but few confirmatory data exist. $^{31}$

However, the ability of transfused RBC to increase oxygen delivery may be reduced because of rapid depletion of red cell nitric oxide content during storage. ${ }^{32}$ Moreover, while the goal of RBC transfusions is to increase the oxygen transport $\left(\mathrm{CaO}_{2}\right)$ and oxygen delivery $\left(\mathrm{DO}_{2}\right)$, the corresponding increase of Hct results in increased blood viscosity which, in turn, decreases blood flow and reduces $\mathrm{DO}_{2}$. Therefore, increasing the Hct in anemia may not correspondingly increase $\mathrm{DO}_{2} \cdot{ }^{33} \mathrm{RBC}$ transfusion-related adverse events may also hamper clinical benefits, with special regard to the socalled not infectious serious hazards of transfusion, which include transfusion-related circulatory overload and, among immune-mediated adverse reactions, transfusion-related acute lung injury. ${ }^{34} \mathrm{~A}$ role of $\mathrm{RBC}$ transfusion in increasing systemic inflammation and erythrocyte slugging in capillary vessels has also been hypothesized. ${ }^{35}$

Whereas the high prevalence and adverse prognostic impact of anemia in patients with ischemic heart disease are recognized, whether it deserves treatment and at which $\mathrm{Hb}$ cutoff level treatment needs to be implemented are still a matter of debate. This is especially true when anemia is part of the systemic inflammatory response syndrome, which is usually seldom associated with severely decreased $\mathrm{Hb}$ concentration.

Even if anemia results from reversible conditions, for example, vitamin or iron deficiencies and immune-mediated hemolysis, days to weeks are usually necessary for its resolution. Therefore, the only readily available treatment is RBC transfusion.

Transfusion has an established role in the setting of acute anemia, whereas its role in chronic anemia, especially of mild degree, is still controversial. A number of studies have focused on which $\mathrm{Hb}$ and/or Hct level should be considered the "adequate transfusion threshold" in critically ill patients or in patients undergoing surgery. ${ }^{36,37}$ 
The debate has centered on 2 distinct transfusion strategies: one is to consider a restrictive threshold, that is, transfusion not indicated until $\mathrm{Hb}$ level $<7-8 \mathrm{~g} / \mathrm{dL}$, and the other is to adopt a more liberal threshold, that is, transfusion not indicated until $\mathrm{Hb}$ level $<9-10 \mathrm{~g} / \mathrm{dL}$. Most data are derived from studies including a mixed population of intensive care unit (ICU) severely ill patients, including those with cardiac disease.

In 1999, Hebert et al published the results of TRICC trial, a multicenter randomized controlled clinical trial that compared the 30 -day mortality among 838 ICU critically ill patients receiving $\mathrm{RBC}$ transfusion according to a restrictive or a liberal strategy. The outcome was similar in the 2 groups. However, the restrictive strategy yielded significantly better results in patients younger than 55 years and in less acutely ill patients without ACS. An analysis of the subgroup with preexisting ischemic heart disease yielded opposite results, with higher mortality rates among those patients managed according to the restrictive strategy ( $26 \%$ vs. $21 \%, p$-value $0.03) .^{38}$

Deans et al reported a commentary about the previous study, its design and results: although the randomization to 2 relatively fixed treatment protocols was the chosen design for simplicity and power, this approach could represent a "practice misalignment" because it applied the fixed therapeutic regimens typical of a clinical trial in a therapeutic area where treatment should be rather influenced by a patient's characteristics and comorbidities. Indeed, the overall outcomes may be influenced by a single misaligned subgroup if patients affected by ischemic heart disease, who would be usually transfused to maintain higher $\mathrm{Hb}$ values, were randomized to the restrictive strategy, and younger and healthier subjects received relative large volumes of RBC. Therefore, these authors suggest developing trial designs that stratify patients into comparable subgroups to help minimize the practice misalignments. ${ }^{39}$

Clinical outcomes according to 2 transfusion strategies were reviewed also by Carson et al in a meta-analysis of $>12,500$ patients enrolled in clinical trials conducted in surgery and ICU subjects. The results were similar to those of the TRICC trial: compared to a liberal strategy, the restrictive one was associated with lower rates of multiple adverse clinical outcomes, including 30-day mortality, myocardial infarction, cerebrovascular accident, recurrent bleeding, pneumonia or thromboembolism. ${ }^{40}$

Data on the association between blood transfusion need and outcome in European ICU patients were obtained from the SOAP study. In this prospective, multicenter, observational study, $33 \%$ of patients received RBC transfusions (mean of transfused units \pm SD: $5.0 \pm 5.8$ ). These patients were older, were more severely ill at admission (according to SAPS II and SOFA score), had longer duration ICU stays and had higher ICU mortality rates. Although there was a direct relation between the number of blood transfusions and the mortality rate, in a multivariate Cox regression analysis including the main confounding factors (sex, age, type of admission, medical history, fluid balance, SOFA score and SAPS II), transfused patients did not have 30-day mortality rates higher than those who were not transfused ${ }^{41}$ This concept was resumed in the related commentary: "the sicker the patient, the more likely the transfusions will be beneficial". ${ }^{42}$

In the setting of moderate-high risk (EuroScore $\geq 6$ ) cardiac surgery, Mazer et al recently compared transfusion strategies in 4806 patients. According to their data, the restrictive strategy was non-inferior to the liberal one with respect to the composite outcome of death and major disability (myocardial infarction, stroke or new-onset renal failure with dialysis). Although no significant differences were identified among the various types of cardiac procedures, the group of patients subjected to only-CABG intervention (26\%) showed an advantage with the liberal approach (unadjusted OR 1.18, 95\% CI: $0.79-1.75){ }^{43}$

A limited number of studies focused on the prognostic impact of RBC transfusion in ACS patients, ${ }^{44-47}$ and results are not uniform also in this setting.

In 2016, Docherty et al published a systematic review and meta-analysis aimed at assessing clinical outcomes for patients affected by cardiovascular disease managed with restrictive or liberal transfusions. Data were derived from 11 randomized trials enrolling 3033 patients for 30-day mortality and from 9 trials with 2609 patients for new cardiovascular events. A restrictive transfusion threshold was associated with an increased risk of ACS in patients with cardiovascular disease: (59 events/1319 patients vs. 32 events/ 1290 patients; risk ratio $1.78,95 \%$ CI: $1.18-2.70$, $p=0.01, I^{2}=0 \%$ for restrictive transfusion). This corresponds to 4.6 episodes of ACS per 100 patients when using restrictive strategies and 2.7 episodes per 100 patients when using liberal strategies. On the other end, the length of hospital stay did not differ between restrictive and liberal transfusion strategies, and no difference was observed in 30-day mortality between the 2 groups. ${ }^{44}$

According to the meta-analysis by Chatterjee et al that included more than 203,600 ACS patients, RBC transfusion was associated with an increase in all-cause mortality and recurrent infarction. ${ }^{45}$ Similar results were reported by Rao 
et al: among 24,112 subjects affected by ACS enrolled in 3 international trials, $10 \%$ of patients underwent at least 1 blood transfusion during the hospitalization, and RBC transfusion was associated with an increased hazard for 30-day death and 30-day death/MI compared with patients who did not receive transfusions. ${ }^{46}$

Different results were obtained by Alexander et al who analyzed RBC transfusion policies and outcomes across 4 distinct nadir Het groups (Hct $\leq 24 \%$ vs. Hct $24.1 \%-27 \%$ vs. Hct $27.1 \%-30 \%$ vs. Hct $>30 \%$ ) in 44,242 patients with NSTEACS enrolled in the CRUSADE registry. RBC transfusion had a favorable impact on in-hospital mortality in patients with a nadir Hct $\leq 24 \%$, whereas higher mortality rates were observed among patients with Hct $>30 \%$. RBC transfusion in patients with intermediate Hct values did not have an impact on mortality. ${ }^{47}$

The picture seems slightly different when the impact of transfusion policies on outcome is analyzed in chronic heart failure patients. The systematic literature review conducted in 2013 by Kansagara et al, which included mainly patients with chronic heart failure, did not find consistent evidence that anemia correction improves outcomes. ${ }^{48}$

Results from clinical studies were incorporated in the most recently published guidelines concerning RBC transfusion policies for critically ill patients, including those with cardiac disease.

The UK National Institute for Health and Care Excellence guideline on blood transfusion, published in November 2015, stated that the optimal transfusion threshold for patients with ongoing ACS should be $8-10 \mathrm{~g} / \mathrm{dL} .{ }^{49}$

Finally, the American Association of Blood Banks "Guidelines on RBC transfusion thresholds and storage" published in $2016^{41}$ recommends a restrictive RBC transfusion threshold for hospitalized, hemodynamically stable adult patients, including critically ill patients, orthopedic and cardiac surgery candidates and patients with preexisting cardiovascular disease. However, these guidelines also state that the restrictive RBC transfusion threshold cannot be applied to ACS patients who are not hemodynamically stable, similar to the 2012 Cochrane review that also recommended the use of a restrictive transfusion trigger, but suggested caution in high-risk groups such as patients with ACS. ${ }^{50}$

Given the absence of solid evidence based on randomized controlled trials, it is probably reasonable to adopt $\mathrm{RBC}$ transfusion in patients with $\mathrm{Hb}$ levels $<8 \mathrm{~g} / \mathrm{dL}$ and to avoid it in patients with $\mathrm{Hb}$ levels $>10 \mathrm{~g} / \mathrm{dL}$. Hb levels between 8 and $10 \mathrm{~g} / \mathrm{dL}$ still represent a "gray area" in which transfusion policies need to be tailored to a specific patient's comorbidities, and may be based on the so-called physiologic transfusion triggers, which might potentially be used to replace arbitrary $\mathrm{Hb}$-based transfusion triggers to estimate the limits of an individual patient's tolerance to anemia.

\section{Alternatives to RBC transfusion}

As in other clinical settings, for example, chronic renal failure, anemia associated with chemotherapy, the use of iron and erythropoiesis-stimulating agents (ESAs) in patients with heart disease have been considered as means to potentially reverse anemia and overcome the need for RBC transfusions.

In studies on anemia associated with chronic heart failure, ${ }^{48}$ moderate-strength evidence suggests that intravenous iron supplements improve New York Heart Association (NYHA) class, exercise tolerance (6-minute walking distance), quality of life and cardiovascular events. ${ }^{51,52}$ However, results were similar in patients with $\mathrm{Hb}$ levels $<$ and $>12 \mathrm{~g} /$ $\mathrm{dL}$ for the Patient Global Assessment ( $p$-value for interaction with $\mathrm{Hb}$ level $=0.98)$, NYHA class ( $p$-value for interaction $=0.51)$ and quality of-life ( $p$-value for interaction $=0.59$ ) outcomes. Moreover, in the setting of ACD, characterized by inhibition of iron absorption and reduction of iron mobilization, the role of iron supplements is reasonably limited and questions its use in improving outcome in anemic patients. Iron supplements are not devoid of adverse effects. Some studies have linked iron administration with oxidative stress and immunomodulatory effects. ${ }^{53}$ Increased risk of infections has also been reported. ${ }^{54}$

In animal models, ESAs were shown to have cytoprotective effects, resulting in the reduction of cellular apoptosis and infarct size, and improvement in ejection fraction. ${ }^{55}$ These results, however, were not confirmed in clinical studies, mainly involving patients with chronic heart failure. In this setting, there is high-strength evidence that ESA use has no beneficial effects on mortality, cardiovascular events and hospitalizations, while ESAs may be associated with hypertension, venous thromboembolism and even increased mortality. $^{48}$

Further studies may clarify the role of ESAs in patients with preserved systolic function or in those with coronary heart disease only.

\section{Conclusion and future prospects}

Anemia is highly prevalent in the ACS setting and is associated with worse outcomes, particularly mortality. Current guidelines recommend correction of anemia $<8 \mathrm{~g} / \mathrm{dL}$, except for hemodynamically unstable ACS patients who 
could benefit from $\mathrm{Hb}$ levels between 8 and $10 \mathrm{~g} / \mathrm{dL}$. RBC transfusion is the only readily available treatment, but it is not a solution without complications. However, the question remains whether anemia has a direct causative role in worsening short- and long-term morbidity and mortality, or if it is rather a marker of a poor clinical condition.

In order to better understand the potential adverse impact of anemia per se, studies focused on selected groups of patients (STEACS vs. NSTEACS) and on specific Hb cutoffs, rather than on generic anemia definitions, could improve our understanding of the still unresolved issue of the impact of anemia in patients with cardiac disease.

\section{Disclosure}

The authors report no conflicts of interest in this work.

\section{References}

1. Wu WC, Rathore SS, Wang Y, Radford MJ, Krumholz HM. Blood transfusion in elderly patients with acute myocardial infarction. $N$ Engl J Med. 2001;345:1230-1236.

2. Archbold RA, Balami D, Al-Hajiri A, et al. Hemoglobin concentration is an independent determinant of heart failure in acute coronary syndromes: cohort analysis of 2310 patients. Am Heart $J$. 2006;152:1091-1095.

3. Meneveau N, Schiele F, Seronde MF, et al; Reseau de Cardiologie de Franche Comte. Anemia for risk assessment of patients with acute coronary syndromes. Am J Cardiol. 2009;103:442-447.

4. Tsujita K, Nikolsky E, Lansky AJ, et al. Impact of anemia on clinical outcomes of patients with ST-segment elevation myocardial infarction in relation to gender and adjunctive antithrombotic therapy (from the HORIZONS-AMI Trial). Am J Cardiol. 2010;105:1385-1394.

5. Sulaiman K, Prashanth P, Al-Zakwani I, et al. Impact of anemia on in-hospital, one-month and one-year mortality in patients with acute coronary syndrome from the middle east. Clin Med Res. 2012;10:65-71.

6. Kunadian V, Mehran R, Lincoff AM, et al. Effect of anemia on frequency of short- and long-term clinical events in acute coronary syndromes (from the acute catheterization and urgent intervention triage strategy trial). Am J Cardiol. 2014;114:1823-1829.

7. Shiraishi J, Kohno Y, Nakamura T, et al; AMI-Kyoto Multi-Center Risk Study Group. Prognostic impact of chronic kidney disease and anemia at admission on in-hospital outcomes after primary percutaneous coronary intervention for acute myocardial infarction. Int Heart $J$. 2014;55(4):301-306

8. Yazji K, Abdul F, Elangovan S, et al. Baseline anemia in patients undergoing percutaneous coronary intervention after an acute coronary syndrome - a paradox of high bleeding risk, high ischemic risk, and complex coronary disease. J Interv Cardiol. 2017;30(5):491-499.

9. Lawler PR, Filion KB, Dourian T, Atallah R, Garfinkle M, Eisenberg MJ. Anemia and mortality in acute coronary syndromes: a systematic review and meta-analysis. Am Heart J. 2013;165:143-153.

10. Salisbury AC, Amin AP, Reid KJ, et al. Hospital-acquired anemia and in-hospital mortality in patients with acute myocardial infarction. $\mathrm{Am}$ Heart J. 2011;162:300-309.

11. Nabais S, Gaspar A, Costa J, et al. Prognostic impact of hemoglobin drop during hospital stay in patients with acute coronary syndromes. Rev Port Cardiol. 2009;28(4):383-395.

12. Meron O, Cladellas M, Recasens L, et al. [In-hospital acquired anemia in acute coronary syndrome. Predictors, in-hospital prognosis and oneyear mortality.] Rev Esp Cardiol. 2012;65(8):742-748. Spanish
13. Hasin T, Sorkin A, Markiewicz W, Hammerman H, Aronson D Prevalence and prognostic significance of transient, persistent, and new-onset anemia after acute myocardial infarction. Am J Cardiol. 2009;104:486-491.

14. Androne AS, Katz SD, Lund L, et al. Hemodilution is common in patients with advanced heart failure. Circulation. 2003;107:226-229.

15. Blanc B, Finch CA, Hallberg L, et al. Nutritional anaemias. Report of a WHO Scientific Group. WHO Tech Rep Ser. 1968;405:1-40.

16. Beutler E, Waalen J. The definition of anemia: what is the lower limit of normal of the blood hemoglobin concentration? Blood. 2006;105:1747-1750.

17. Patel KV. Variability and heritability of hemoglobin concentration: an opportunity to improve understanding of anemia in older adults. Haematologica. 2008;93:1281-1283.

18. Morici N, Cantoni S, Antonicelli R, et al. Anemia in octogenarians with non-ST elevation acute coronary syndrome: aging or disease? Int J Cardiol. 2014;176:1147-1149.

19. Joosten E, Pelemans W, Hiele M, et al. Prevalence and causes of anaemia in a geriatric hospitalized population. Gerontology. 1992;38:111-117.

20. Izaks GJ, Westendorp RG, Knook DL. The definition of anemia in older persons. JAMA. 1999;281:1714-1717.

21. Mancini DM, Katz SD, Lang CC, et al. Effect of erythropoietin on exercise capacity in patients with moderate to severe chronic heart failure. Circulation. 2003;107(2):294-299.

22. Cash JM, Sears DA. Anemia of chronic disease: spectrum of associated diseases in a series of unselected hospitalized patients. Am J Med. 1989;87:638-644.

23. Weiss G, Goodnough LT. Anemia of chronic disease. $N$ Engl J Med. 2005;352(10):1011-1023.

24. Bullen JJ, Rogers HJ, Spalding PB, Ward CG. Iron and infection: the heart of the matter. FEMS Immunol Med Microbiol. 2005;43(3): 325-330.

25. Marx JJ. Iron and infection: competition between host and microbes for a precious element. Best Pract Res Clin Haematol. 2002;15(2):411-426.

26. Mamas MA, Kwok CS, Kontopantelis E, et al. Relationship between anemia and mortality outcomes in a national ACS cohort: insights from the UK MINAP registry. J Am Heart Assoc. 2016;5:e003348

27. Solomon A, Blum A, Peleg A, Lev EI, Leshem-Lev D, Hasin Y. Endothelial progenitor cells are suppressed in anemic patients with acute coronary syndrome. Am J Med. 2012;125:604.

28. Shander A, Javidroozi M. The patient with anemia. Current Opinion Anesthesiology. 2016;29(3):438-445.

29. Sudarsky D, Sudarsky M, Matezky S, et al. Impact of early invasive approach on outcomes of patients with acute coronary syndrome and baseline anemia: analysis from the ACSIS registry. J Interven Cardiol. 2015;28:315-325.

30. Lee SH, Jeong MH, Han KR, et al. Comparison of transradial and transfemoral approaches for percutaneous coronary intervention in patients with acute coronary syndrome and anemia. Am J Cardiol. 2016;117:1582-1587.

31. Farhan S, Baber U, Mehran R. Anemia and acute coronary syndrome: time for intervention studies. J Am Heart Assoc. 2016;5:e04908.

32. Pawloski JR, Stamler JS. Nitric oxide in RBCs. Transfusion. 2002;42:1603-1609.

33. Zimmerman R, Tsai AG, Salazar Vázquez BY, et al. Posttransfusion increase of Hematocrit per se does not improve circulatory oxygen delivery due to increased blood viscosity. Anesth Analg. 2017;124: $1547-1554$.

34. Hendrickson JE, Hillyer CD. Noninfectious serious hazards of transfusion. Anesth Analg. 2009;108(3):759-769.

35. Tsai AG, Cabrales P, Intaglietta M. Microvascular perfusion upon exchange transfusion with stored red blood cells in normovolemic anemic conditions. Transfusion. 2004;44:1626-1634.

36. Du Pont-Thibodeau G, Harrington K, Lacroix J. Anemia and red blood cell transfusion in critically ill cardiac patients. Ann Intensive Care. 2014;4:16 
37. Carson JL, Sieber F, Cook DR, et al. Liberal versus restrictive blood transfusion strategy: 3-year survival and cause of death results from the FOCUS randomised controlled trial. Lancet. 2015;385(9974):1183-1189.

38. Hebert PC, Wells G, Blajchman MA, et al. A multicentre, randomized, controlled clinical trial of transfusion requirements in critical care. $N$ Engl J Med. 1999;340:409-417.

39. Deans KL, Minneci PC, Suffredini AF, et al. Randomization in clinical trials of titrated therapies: unintended consequences of using fixed treatment protocols. Crit Care Med. 2007;35:1509-1516.

40. Carson JL, Guyatt G, Heddle NM, et al. Clinical practice guidelines from the AABB red blood cell transfusion thresholds and storage. JAMA. 2016;316(19):2025-2035.

41. Vincent JL, Sakr Y, Sprung C, et al. Are blood transfusions associated with greater mortality rates? Results of the sepsis occurrence in acutely ill patients study. Anesthesiology. 2008;108:31-39.

42. Vincent JL, Lelubre C. The sicker the patient, the more likely that transfusion will be beneficial. J Thorac Dis. 2017:9:4912-4914.

43. Mazer CD, Whitlock RP, Fergusson DA, et al; TRICS Investigators and Perioperative Anesthesia Clinical Trials Group. Restrictive or liberal red-cell transfusion for cardiac surgery. $N$ Engl J Med. 2017;377:2133-2144.

44. Docherty AB, O’Donnell R, Brunskill S, et al. Effect of restrictive versus liberal transfusion strategies on outcomes in patients with cardiovascular disease in a non-cardiac surgery setting: systematic review and metaanalysis. BMJ. 2016;352:i1351.

45. Chatterjee S, Wetterslev J, Sharma A, et al. Association of blood transfusion with increased mortality in myocardial infarction: a meta-analysis and diversity-adjusted study sequential analysis. JAMA Intern Med. 2013;173(2):132-139.

46. Rao SV, Jollis JG, Harrington RA, et al. Relationship of blood transfusion and clinical outcomes in patients with acute coronary syndromes. JAMA. 2004;292:1555-1562.
47. Alexander KP, Chen AY, Wang TY, et al. Transfusion practice and outcomes in non-ST-segment elevation acute coronary syndromes. Am Heart J. 2008;155:1047.

48. Kansagara D, Dyer E, Englander H, et al. Treatment of anemia in patients with heart disease. A systematic review. Ann Intern Med. 2013;159: 746-757.

49. National Institute for Health and Clinical Excellence. Transfusion: NICE guideline NG24. 2015. Available from: http:/www.nice.org.uk/ guidance/ng24/evidence/full-guidance-2177160733.

50. Carson JL, Carless PA, Hebert PC. Transfusion thresholds and other strategies for guiding allogeneic red blood cell transfusion. Cochrane Database Syst Rev. 2012;4:CD002042.

51. Anker SD, Comin Colet J, Filippatos G, et al; FAIR-HF Trial Investigators. Ferric carboxymaltose in patients with heart failure and iron deficiency. N Engl J Med. 2009;361:2436-2448.

52. Comin-Colet J, Lainscak M, Dickstein K, et al. The effect of intravenous ferric carboxymaltose on health related quality of life in patients with chronic heart failure and iron deficiency: a subanalysis of the FAIR-HF study. Eur Heart J. 2013;34:30-38.

53. Koskenkorva-Frank TS, Weiss G, Koppenol WH, Burckhardt S. The complex interplay of iron metabolism, reactive oxygen species, and reactive nitrogen species: insights into the potential of various iron therapies to induce oxidative and nitrosative stress. Free Radic Biol Med. 2013;65:1174-1194.

54. Litton E, Xiao J, Ho KM. Safety and efficacy of intravenous iron therapy in reducing requirement for allogeneic blood transfusion: systematic review and meta-analysis of randomised clinical trials. BMJ. 2013;347:f4822.

55. Ruifrok WPT, Lipsic E, de Boer RA, et al. Erythropoiesis stimulation in acute ischemic syndromes. Heart Failure Clin. 2010;6:313-321.
Vascular Health and Risk Management

\section{Publish your work in this journal}

Vascular Health and Risk Management is an international, peerreviewed journal of therapeutics and risk management, focusing on concise rapid reporting of clinical studies on the processes involved in the maintenance of vascular health; the monitoring, prevention and treatment of vascular disease and its sequelae; and the involvement of

\section{Dovepress}

metabolic disorders, particularly diabetes. This journal is indexed on PubMed Central and MedLine. The manuscript management system is completely online and includes a very quick and fair peer-review system, which is all easy to use. Visit http://www.dovepress.com/ testimonials.php to read real quotes from published authors. 